\title{
A CONTRIBUIÇÃO DO CONTADOR PARA O MICROEMPREENDEDOR INDIVIDUAL
}

\section{ARTIGO ORIGINAL}

FERMIN, Joicy Suziane Gomes ${ }^{1}$, GARCIA, Yasmin Sales², ROBERTO, José Carlos Alves $^{3}$, SERRA, Meg Rocha da Cunha ${ }^{4}$, LOPES, Nelânia Ferreira ${ }^{5}$

FERMIN, Joicy Suziane Gomes. Et al. A contribuição do contador para o microempreendedor individual. Revista Científica Multidisciplinar Núcleo do Conhecimento. Ano. 06, Ed. 10, Vol. 03, pp. 145-163. Outubro 2021. ISSN: 24480959, Link de acesso:

https://www.nucleodoconhecimento.com.br/contabilidade/contribuicao-do-contador, DOI: 10.32749/nucleodoconhecimento.com.br/contabilidade/contribuicao-docontador

\section{RESUMO}

Os microempreendedores precisam de um norte para os seus negócios, com isso, a contabilidade pode ajudá-los a terem maior destaque no mercado, visto que, oferece a eles informações contábeis sobre a situação que a empresa se encontra. $\mathrm{O}$ objetivo deste estudo é mostrar a importância da contabilidade para o microempreendedor individual (MEI) e para seu negócio. Quanto aos objetivos específicos: examinar a frequência de uso das ferramentas contábeis do MEl; analisar a utilidade do setor contábil nos processos de tomada de decisão, principalmente gerencial e demonstrar ao microempreendedor o quanto a contabilidade é essencial para sua empresa. A contabilidade é útil para o

\footnotetext{
${ }^{1}$ Graduanda do curso de Contabilidade.

${ }^{2}$ Graduando do curso de Contabilidade.

${ }^{3}$ Orientador. Mestre em Engenharia de produção. Especialista Logística empresarial. Graduado em Administração com Ênfase em Marketing.

${ }^{4}$ Orientadora. Mestra em Engenharia de Processos Industriais pela UFPA, especialista em Controladoria e Auditoria Contábil pelo Ciesa (2020), Graduada em Ciências Contábeis pelo Centro Universitário do Norte (2010). Graduada em Ciências Econômicas pelo Centro Universitário do Norte (2006).

${ }^{5}$ Orientadora. Especialista em Auditoria Contábil, Financeira e Tributária e Graduada em Ciências Contábeis.
}

RC: 98793

Disponível em: 
microempreendedor, pois permite que ele tome decisões assertivas para sua microempresa. Sendo assim foi levantada a seguinte pergunta: de que forma se pode demonstrar a relevância da contabilidade para o MEI? Para realização desse artigo foi utilizado pesquisa bibliográfica com base na abordagem qualitativa e quanto aos meios têm como principal foco analisar os problemas que são encontrados no decorrer do estudo. Portanto, conclui-se que é de suma importância a contribuição do contador para as empresas, principalmente para o $\mathrm{MEI}$, na qual o contador tem um papel indispensável na sua empresa, onde ele orienta, auxilia e faz com que a empresa se organize, encaminhando-a ao sucesso.

Palavras-chave: Microempreendedor Individual, Contabilidade, Microempresa.

\section{INTRODUÇÃO}

A contabilidade é utilizada para ajudar os empresários e os MEls que trabalham de forma autônoma. Após realizar o cadastro da microempresa, ela passa a ter direitos e deveres, tendo em vista que esta é uma nova opção de empreender com menos burocracia. No entanto, mesmo que não seja um processo tão burocrático, ainda há a necessidade de auxílio de um contador, a despeito dos impostos baixos e da não exigência deste. Machado (2012) ressalta que o MEl possui como característica um empresário legalizado que irá trabalhar por conta própria.

Apesar disso ainda há microempreendedores que necessitam de informações contábeis para organizar suas ações dentro dos seus negócios, como o contador que pode atuar como departamento pessoal que irá auxiliar o microempreendedor no processo de contratação de funcionários.

Diante disso, o objetivo dessa pesquisa é mostrar a importância da contabilidade para o MEI e para o seu negócio. Com a oportunidade de formalização das microempresas, criou-se a oportunidade de elas impulsionarem seus lucros, contudo, as normas fiscais e tributárias podem ser complicadas, fazendo com que o auxílio de um contador seja fundamental para o microempreendedor. 
Quanto aos objetivos específicos, o trabalho visa examinar a frequência de uso das ferramentas contábeis; analisar a utilidade do setor contábil nos processos de tomada de decisão, principalmente gerencial e demonstrar ao microempreendedor o quanto a contabilidade é essencial para sua empresa.

Os microempreendedores precisam de um norte para os seus negócios, com isso, a contabilidade exerce o papel de auxiliar novos empresários a se destacarem dentro do mercado, visto que, ela oferece informações contábeis sobre a situação em que a empresa se encontra. Considerando que a falta de informações contábeis pode ocasionar tomadas de decisões erradas, as quais têm a possibilidade de prejudicar a empresa, surgiu-se o seguinte questionamento: de que maneira é possível demonstrar a relevância da contabilidade para o MEI?

Portanto, espera-se com esse estudo contribuir com a comunidade acadêmica, científica e com os novos MEls sobre a importância que o contador possui.

\section{FUNDAMENTAÇÃO TEÓRICA}

A fundamentação é a parte do trabalho em si, onde é apresentado o assunto aprofundado sobre o tema e seu desdobramento. A partir daqui será abordado sobre a contabilidade para o MEI e todas as vantagens que o contador pode oferecer para ele. Gil (2017) ressalta que a fundamentação teórica é a parte do desenvolvimento em que serão discutidas teorias de autores a respeito do tema da pesquisa. Diante do que foi exposto acima, foi construído o referencial teórico que alcance os objetivos propostos no decorrer dessa pesquisa.

\subsection{A CONTABILIDADE E SUA EVOLUÇÃO AO LONGO DO TEMPO}

A contabilidade é entendida como o conjunto de bens e direitos dependente que tenha ou não fins lucrativos, mas que seja possível avaliar a moeda. A contabilidade também possui algumas funções básicas que são administrar a economia além de fornecer informações sobre o controle financeiro e econômico da empresa. Além 
disso, a contabilidade sempre esteve presente na vida do homem, pois é ela que pode auxiliar as empresas a tomarem força a cada dia, sua função é fornecer informações que irão ajudar a melhor administração do patrimônio, pois o homem sentiu a necessidade de registrar e organizar os próprios bens (LOPES; BURIOLA, 2019).

A contabilidade também se mostra uma opção de suporte para as empresas porque a cada período elas têm mais controle de suas utilidades, até os dias atuais e desde os tempos mais antigos. Ela também oferece uma gama de dados para as organizações tanto de pequeno quanto de grande porte. O surgimento da contabilidade pode ser confundido com a história da própria humanidade, pois a contabilidade surgiu há muito tempo, desde o tempo antigo quando a escrituração contábil era feita apenas em pedras e até mesmo tábuas, assim é possível notar a necessidade que o homem sentiu de organizar seus bens. A contabilidade é uma ciência, no entanto sua existência não é nova, e sim antiga, pois o homem primitivo já praticava contabilidade (AGOSTINI; CARVALHO, 2012).

Conforme Olivo e Boschilia (2012) a contabilidade pode ter surgido antes mesmo da escrita lá na idade média que pode ser vista mais tarde em sítios arqueológicos que faz parte dos conhecimentos mais antigos que a humanidade possa ter de como a contabilidade se torna indispensável na vida da empresa e dos negócios, pois se apresenta como grande pilar.

Ainda conforme Greco e Arend (2016), a origem da contabilidade tem um sentido primitivo, mas o fato é que o homem ao tentar se expressar em suas primeiras inscrições em pedra, madeira expressando de alguma forma a contabilidade na demonstração de resultados, pois quando pescava ou tinha caças ele preocupavase em saber os resultados obtidos. Diante disso, é possível notar o quanto o papel da contabilidade está atrelado ao passado caminhando sempre lado a lado com a humanidade, porém em constante evolução, pois com o passar do tempo a maneira de realizar esses registros modificou-se. 
Houve uma época a qual o profissional da contabilidade era tido como o "guarda livros", pois tinha como função fazer a escrituração e manter a ordem dos livros de empresas comerciais, além disso esse trabalho exigia pouca especialização e pouco conhecimento científico, visto que a forma de se fazê-lo era de forma manual (BASTOS FILHO, 2019).

Todavia, isso foi mudando sendo criado outros meios mais simples de se fazer a contabilidade com novos recursos favorecendo a utilização dela, pois, a contabilidade houve avanços ao decorrer da história, como na antiguidade que se utilizava pedras para fazer a contagem, ou como atualmente que são utilizados programas e softwares mais avançados (LUNELLI, 2021).

Pode-se dizer que a contabilidade se tornou cada vez mais importante com o passar dos anos, no cenário mundial os avanços tecnológicos proporcionaram aos profissionais da área contábil, uma busca cada vez mais rápida de maneiras para melhorar cada vez mais a qualidade dos serviços prestados. Ao longo do tempo a Contabilidade sofreu grandes mudanças, principalmente no que diz respeito aos avanços tecnológicos da era digital e assim os profissionais da contabilidade muitas vezes encontram dificuldades para acompanhar este processo que cresce intensamente, pois há constantes mudanças e novos recursos que surgem modificando o modo de se fazer a contabilidade (COSTA; FEITOSA FILHO, 2019).

$\mathrm{Na}$ atualidade, são muitas as obrigações exigidas pelas empresas, como informações em tempo real para tomadas de decisões, frente ao mercado competitivo, além disso, os grandes avanços tecnológicos tem como objetivo facilitar a forma de trabalho das empresas, dessa maneira, os escritórios de contabilidade vem buscando se adequar às mudanças trazidas pela nova era digital para o cumprimento das obrigações exigidas por lei, assim, os processos que antes eram feitos de forma manual que levava dias para estarem prontos hoje é feito em questão de horas ou até mesmo minutos (VOLNEI et al., 2010). 
Em outras palavras, a área contábil está em constante avanço tecnológico, facilitando informações de maneira mais centralizada e ágil, diminuindo fraudes e sonegação de impostos. Hoje existem vários subprojetos, alguns já ativos e outros ainda em fase de teste, dos quais os principais são nota fiscal eletrônica, escrituração contábil digital, escrituração fiscal digital. Entretanto, apesar de todo o avanço tecnológico e os benefícios que traz para se trabalhar de forma mais rápida e ágil com uso que as ferramentas que as novas tecnologias oferecem, muitos profissionais da contabilidade ainda sentem dificuldades para se adaptarem com os avanços da era digital na área contábil (TESSMANN, 2011).

Por conseguinte, desde os tempos mais antigos que a contabilidade vem evoluindo e atualmente surgem as novas tecnologias e novos avanços que impactam a maneira de se fazer a contabilidade, pois ela sofre mudanças trazidas pelos novos recursos tecnológicos, é o caso da indústria 4.0 é uma nova realidade que implica a adoção gradual do uso das tecnologias e na formação de um sistema de informações que possibilitam informações rápidas e diretas. Para Coelho (2016), o impacto da Indústria 4.0 passa por uma forma muito mais complexa de inovação, pois ela se baseia na combinação de múltiplas tecnologias, que obrigaram as empresas a reverem a forma de como gerem os seus negócios e processos.

O que se pode perceber é que a tecnologia deixou de ser meramente um sistema de processo operacional, e passou a ser considerada um recurso estratégico no negócio que é essencial para a sua saúde financeira e a gestão do seu patrimônio, pode ser também bastante difícil adaptar-se a ela por conta dos novos recursos que surgem. O mundo também se tornou cada vez mais globalizado e utilizando as tecnologias, além disso um sistema de processo deixou de ser apenas um sistema operacional e passou a integrar e ajudar como recurso estratégico na empresa (TESSMANN, 2011).

Atualmente a internet dentro das empresas e escritórios contábeis vem auxiliando no processo mais ágil e prático devido ao surgimento de novos sistemas que tratam informações e remetem a órgãos competentes, ajudando cada vez mais na melhoria 
de se fazer a contabilidade. A contabilidade é tão importante e necessária, porque está ligada a forma como se faz os registros, a situação da empresa.

A era digital trouxe inovações para a forma de se fazer a contabilidade e o contador precisa se adequar a esses novos sistemas, buscando conhecimentos e se aprimorando, pois, os novos sistemas que surgem precisam de aprimoramento e uso por parte do profissional que utiliza. A contabilidade devido aos novos avanços tecnológicos surgidos na era digital fazem com que seja necessário o constante aprimoramento e adequação a esses novos recursos que surgem devido aos impactos da indústria 4.0, ao mesmo tempo que esses recursos são serviços exigidos pelos novos clientes, pois criam oportunidades de serem realizados com mais rapidez através dos profissionais da contabilidade, a qual desenvolvida de forma integrada e adequada às necessidades das entidades, permite uma maior flexibilidade, eficiência (STAATS; DE MACEDO, 2021).

Dessa forma, a contabilidade evoluiu ao longo dos anos e é tão necessária dentro das empresas, escritórios contábeis e para saber toda movimentação financeira que a empresa possui, porque a contabilidade é usada há muito tempo, desde os primórdios da civilização antiga, mas com o passar do tempo ela tornou-se fundamental e importante para a gestão de negócios das empresas.

\subsection{O MICROEMPREENDEDOR INDIVIDUAL E A CONTABILIDADE}

A contabilidade é essencial dentro das organizações e para o MEI não seria diferente, pois ela pode auxiliar a controlar as finanças, principalmente em relação às finanças pessoais, a contabilidade permite para a pessoa que administra a empresa realizar modificações no patrimônio, pois ele conhece e saberá as mudanças necessárias que serão melhores para a organização. Permite também saber a origem dos recursos e como estão sendo aplicados. Dessa maneira, a contabilidade surge para auxiliar no que concerne aos negócios da empresa e na melhor decisão que será tomada para melhorar os negócios (BRINCKMANN, 2014).

RC: 98793

Disponível em:

https://www.nucleodoconhecimento.com.br/contabilidade/contribuicao-do-contador 
A contabilidade se torna útil para o $\mathrm{MEI}$ porque permite que ele tome decisões assertivas para sua microempresa. Além disso, a falta de informação contábil pode acarretar danos e riscos para o andamento dos negócios uma vez que o microempresário precisa de informações fiscais e tributárias, mas não somente isso, é utilizado para formalizar esse novo empreendedor onde ele é incluído na política de previdência e a partir disso ele saberá todas suas obrigações e deveres sobre seu novo negócio (AMORIM; CARDOSO, 2021).

Além disso, um dos principais objetivos da contabilidade é ajudar a empresa e o $\mathrm{MEI}$, fornecendo informações essenciais para o desenvolvimento da economia e na decisão por parte dos gestores da empresa que irão permitir uma base confiável para o comando da organização, auxiliando assim os negócios. De acordo com Paiva et al. (2020) a contabilidade é ferramenta fundamental e indispensável para a gestão do negócio de qualquer empresa, seja ela de micro, médio ou grande porte.

A contabilidade como ciência possibilita a mensuração de resultados da empresa. Ela pode ajudar o microempreendedor a saber como lidar com as situações que surgirem. Vale ressaltar que existe a Lei 128/2008 que trata sobre questões do MEI, mas não há uma cláusula específica que obrigue o MEl a ter um contador, tendo em vista que o lucro não pode ultrapassar $\mathrm{R} \$ 81.000,00$ anualmente (SOUZA et al., 2021).

No entanto, a contribuição do contador ajudará para que esse novo microempresário possa optar pelo melhor caminho a seguir na empresa, visto que o contador dará suporte ao tomar uma decisão que afetará os negócios. O contador tem esse papel por oferecer suporte aos clientes para registrar e analisar as mudanças que ocorrem dentro da empresa, norteando ao melhor caminho para as finanças (COSTA; FEITOSA FILHO, 2019).

Por conseguinte, o empreendedor tem um controle mais preciso do faturamento, o contador também poderá dar suporte ao microempreendedor com questões trabalhistas na hora de contratar um funcionário. Por exemplo, em relação à licença 
maternidade e férias. Em síntese o contador é um profissional que vai ajudar nos negócios e pode melhorar os processos de forma eficiente. A contabilidade é uma assessoria às empresas que se desenvolve a cada dia. Visto que as empresas contraem um máximo controle da parte financeira e econômica e assim constitui-se uma etapa importante na tomada de decisão em diversas esferas. Dessa maneira, o profissional da contabilidade é um importante aliado para as empresas, em especial aos MEls, porém, as tomadas de decisões são decisivas para impedir riscos em posicionamentos ilícitos, afetando a assiduidade da empresa. (SOUZA et al., 2021).

Percebe-se então que o setor contábil vai além da escrituração de documentos fiscais, podendo atuar ainda no gerenciamento de ações que dirijam o empresário no processo de tomada de decisão. No entanto, a contabilidade pode ser útil em todas as áreas da organização, pois através dela são fornecidos relatórios que aprovam se a empresa está em uma situação econômica positiva ou não (TESSMANN, 2011).

A contabilidade torna-se tão essencial para o novo microempresário, principalmente nas questões tributárias, para apurar os impostos, além de poder disponibilizar ferramentas necessárias para a formação de preço e margem de lucro quando ele vir a precisar. É por meio da contabilidade que um profissional poderá dar suporte para o bom funcionamento dos negócios, por exemplo, criar um plano de contas e definir questões tributárias da empresa. (VOLNEI et al., 2010).

A partir de uma contabilidade bem-feita que o negócio poderá transparecer a ética, impulsionar os negócios e dar credibilidade para os clientes que irão depositar confiança nela. Ademais, o empreendimento bem estruturado gera dados que são capazes de contribuir para alternativas em caso de algum problema financeiro que possa surgir no decorrer do tempo. O profissional que ajuda o novo empresário a administrar a parte financeira da empresa pode impulsionar o crescimento do empreendimento. Portanto, a contabilidade para o microempreendedor está atrelada também à aquisição de novos conhecimentos contábeis que servirão para o sucesso do MEI (CHUPEL et al., 2014).

RC: 98793

Disponível em:

https://www.nucleodoconhecimento.com.br/contabilidade/contribuicao-do-contador 
Diante do que foi exposto acima, percebe-se que a contabilidade é essencial não somente para apresentar informações econômicas para a empresa, mas para ajudar no processo de decisões que se tornam essenciais para os negócios, além de auxiliar na objetividade de informações que são construídas para atender seu consumidor final.

\subsection{A CONTABILIDADE GERENCIAL}

A contabilidade gerencial visa gerar procedimentos contábeis que forneçam informações valiosas para o processo de decisões dentro da empresa. É a partir da utilização dela que quem administra a empresa passa a saber mais sobre ela e poderá tomar decisões que irão dar suporte a mesma. A parte do gerenciamento contábil tem como foco o maior índice de acertos nas previsões e avaliações que a empresa processará no sistema de informações, a fim de armazenar dados que auxiliem as tomadas de decisões que afetarão a sobrevivência da empresa (GARCIA; BEZERRA, 2021).

Porque a decisão é a resposta ao problema porque os gestores precisam de agilidade para tomar uma decisão que pode afetar a empresa a contabilidade gerencial proporciona sucesso para organização, porque segundo Crepaldi (2013), a contabilidade gerencial é um segmento dentro da própria contabilidade que tem por finalidade dar suporte aos administradores da organização em suas funções gerenciais. Está voltada também para utilizar recursos de economia por meio de um adequado sistema de controle gerencial.

Ela também tem como principal foco a análise dos custos e finanças que ajudam a fornecer informações imprescindíveis para o processo de escolhas dentro da corporação, ela permite também que a empresa faça uma análise em relação à concorrência no mercado financeiro, sabendo assim como projetar os negócios bem como os aspectos internos e externos. Por conseguinte, a contabilidade gerencial permite que a empresa a partir dessa ferramenta importante passe a enxergar além dos números para interpretar melhor os resultados obtidos. Também está presente 
na atualidade, principalmente na gestão de negócios, por esse motivo é essencial uma resposta de sucesso ao mercado com informações claras e confiáveis (SOUZA et al., 2021).

A contabilidade gerencial também pode ser vista como um auxílio às micro e pequenas empresas porque as empresas que estão no mercado quando não há um bom planejamento podem ir à falência. Dessa maneira, as demonstrações contábeis elaboradas pelo contador podem ir de encontro às metas da empresa, assim é importante destacar que de acordo com Beuren et al. (2013) às micro e pequenas empresas precisam crescer e ser competitivas dentro do mercado e a contabilidade gerencial é um forte sistema para isso.

Portanto, torna-se essencial para planejar e controlar a empresa a partir das informações contábeis tornando-se assim crucial para o conhecimento evitando os riscos nos processos de decisões, pois tem como objetivo principal o funcionamento interno da organização, permite serviços eficientes e de maior qualidade, assim a partir do seu uso pode-se reduzir custos e aumentar a competição dentro do mercado competidor.

\subsection{VANTAGENS PARA O EMPREENDEDOR OPTAR PELA MICROEMPRESA INDIVIDUAL}

O brasileiro é um povo empreendedor e a opção pelo empreendedorismo lhe traz inúmeras facilidades porque no portal do MEI que é o site do governo brasileiro oferece muitos benefícios, tais como: cobertura previdenciária, acesso e apoio técnico do SEBRAE, baixo custo mensal e poderá até mesmo vender para o governo. A informação contábil é de grande importância para os novos microempreendedores, pois, sem uma orientação correta existem sérios riscos para a direção da empresa, desta forma, com uma orientação correta o gestor adquire maior segurança e credibilidade para a tomada de decisão precisa e eficaz (CERQUEIRA, 2020). 
O contador ajuda principalmente na finalidade fiscal, além disso, pode auxiliar o microempreendedor. Diante disso, é o profissional da contabilidade que possui papel de relevância dentro de uma empresa, porque além de saber utilizar de todos os recursos de sua profissão, ele também orienta a empresa e faz com que ela se mantenha organizada, justamente para se mostrar diferente dos demais concorrentes.

Mas antes de falar sobre a contabilidade e sua relação na vida do MEI, é necessário mostrar quais os requisitos necessários para que este empresário seja considerado MEI. São eles: trabalhar de forma individual; possuir um faturamento de até 81 mil reais de forma anual e que possua apenas um trabalhador. O processo de formalização do MEI é feito de forma gratuita em qualquer época do ano, eletronicamente pelo Portal do Simples Nacional em "Simei" e busca pela opção de enquadramento e seguir todas as etapas que serão indicadas para criação da microempresa. É necessário saber também que terá um desconto de um valor fixo mensal sobre o INSS, ICMS, TSS. Também precisará cumprir os seus deveres, por exemplo, preencher o relatório mensal de receitas. $O$ novo MEI também pode realizar a contratação pagando salário-mínimo (SEBRAE, 2020).

O MEI é o empresário legalizado que trabalha de maneira própria. A partir do avanço e da necessidade do mercado, foram surgindo os trabalhadores informais e ainda quando Luiz Inácio Lula da Silva era presidente, houve uma mudança na lei (123/06) que complementa com a lei (128/08) resultando no MEl. Algumas das vantagens de realizar a legalização por meio do $\mathrm{MEI}$ são as seguintes vantagens: ter uma empresa formal e legalizada conforme rege a lei; INSS, a possibilidade de realizar compras mais baratas, emissão de nota fiscal são alguns dos benefícios.

Foi criado no Brasil com intuito de legalizar os trabalhadores informais a trabalharem dentro da legalidade das leis em que eles tenham chances de crescimento no seu negócio além de alavancar as vendas. Para ser um MEl é necessário ter um teto base mensal de renda para poder realizar o cadastro de forma eletrônica. A partir da lei complementar 123 que é conhecida também como a lei das micro e pequenas

RC: 98793

Disponível em:

https://www.nucleodoconhecimento.com.br/contabilidade/contribuicao-do-contador 
empresas, criada no ano de 2006 com o intuito de minimizar a burocracia para os pequenos empresários e facilitar a abertura de novas pequenas empresas. Em resumo, esse trabalhador exerce a profissão de produção e articulação de bens e serviços.

Diante disso, a contabilidade é primordial nas organizações e na vida do microempreendedor não seria diferente, pois, ajuda-o a controlar as finanças, principalmente as finanças pessoais. A contabilidade se torna útil, pois, contribui com o processo decisório. Além disso, a falta de orientação contábil pode gerar danos e riscos, uma vez que ele precisa de informações contábeis e fiscais. Assim a contabilidade é útil, para adquirir informações contábeis corretas sobre a real situação da empresa, pois a contabilidade mostra informações econômicas com principal objetivo de gerenciar o patrimônio de maneira eficaz.

\subsection{SISTEMA TRIBUTÁRIO BRASILEIRO}

De maneira geral o brasileiro paga muito imposto, sendo assim, no cenário atual um dos temas importantes a serem discutidos é o sistema tributário brasileiro, pois ele tem uma imensa complexidade e a carga tributária que é de fato muito alta, equivale a 33\% do Produto Interno Bruto. Se comparar a carga tributária do Brasil com as de outros países que estejam mais ou menos no mesmo nível de desenvolvimento, a carga tributária brasileira é muito mais alta, até mesmo do que as de países muito mais desenvolvidos (MAZZA, 2018).

Compreender como funciona o sistema tributário brasileiro é algo bem complexo, pois é necessário entendimento sobre a questão da carga tributária que é um dos pontos principais a serem observados pelo empresário brasileiro e para quem deseja abrir o próprio negócio, segundo Chiavenato (2012), a empresa possui muitos desafios ao se ampliar em um mercado totalmente competitivo.

Como por exemplo, compreender o impacto que ela causa no dia a dia do trabalho e na tomada de decisão dentro da organização requer atenção especial, pois há a 
necessidade de lidar com o problema que ela gera, sendo assim para lidar melhor com o problema para ter um planejamento e controle sobre ela. Assim, de acordo com o grupo BLB Brasil (2018), existem as principais tributações fiscais a serem observadas pelo empresário: Imposto sobre o Produto Industrializado; Imposto de Renda Pessoa Jurídica; Contribuição para o Programa de Integração Social. Por conseguinte, ainda há contribuição social que incide sobre o Faturamento das Empresas e o Imposto que é cobrado sobre Importações, ambos federais.

Além desses impostos fiscais há outros impostos, por exemplo, o ICMS que é o imposto sobre circulação de mercadorias e prestação de serviços. O custeio bastante exagerado e a burocracia acabam sendo entraves para abrir e regulamentar uma empresa no Brasil. No Brasil os números dos tributos superam outros países que são mais desenvolvidos, isso demonstra que há uma necessidade de mudanças no que diz respeito às regras para abrir uma empresa e na redução da arrecadação dos impostos, principalmente para as pequenas empresas.

O sistema tributário traz impactos para a vida dos empresários e dos empreendedores que desejam abrir o próprio negócio porque com os impostos crescentes as empresas buscam meios para que possa ocorrer a diminuição dos valores que são pagos, realizando muitas das vezes, observações internas para que possa identificar a melhor forma de economizar, sem sair das normas e leis vigentes, pois as altas cargas de tributos e impostos impactam diretamente no desenvolvimento da empresa, dessa maneira, é necessário um planejamento (CHAVES; MUNIZ, 2012).

\subsection{EMPREENDEDORISMO}

O empreendedorismo é conhecido também como um forte fator para o crescimento econômico das nações, mas não somente isso, o empreendedor também possui uma visão acerca dos negócios, uma oportunidade onde não existia porque o microempreendedor possui uma visão que poderá alimentar o futuro. E muitas vezes essas novas ideias e estratégias podem estar ligadas ao ato criativo que possibilita

RC: 98793

Disponível em:

https://www.nucleodoconhecimento.com.br/contabilidade/contribuicao-do-contador 
que ele possa lidar melhor com o mundo que o cerca. O micro empreendedorismo no MEl busca perceber quais as necessidades nos negócios e com isso oferecer um serviço ou produto que possa superar isso (CERQUEIRA, 2020).

De acordo com Behling e Lenzi (2016) existe uma competitividade nas microempresas que está fortemente ligada pelas competências do microempreendedor, pois as competências empreendedoras estão atreladas às características e competências que a pessoa irá desenvolver dentro dos negócios. Ademais, o microempreendedor desenvolve esforços e recursos para colocar a sua ideia em prática visando buscar informações para o seu planejamento e metas. É nesse momento que surge também o comportamento estratégico para que ele possa se manter competitivo no mundo dos negócios.

Por conseguinte, existem dois tipos de microempreendedores: aquele que surge para sobreviver em meio à crise econômica e aquele que surge após uma oportunidade e ideia que visa contribuir de forma positiva com a economia. $\mathrm{O}$ microempreendedor pode ser considerado como um importante avanço rumo à liberdade de novos negócios (GONDIM et al., 2018).

\section{MATERIAIS E MÉTODOS}

Os materiais e métodos são os planejamentos detalhados sobre tudo o que será concretizado ao decorrer da pesquisa e como será aplicada para atingir os seus objetivos, ou seja, irá descrever de forma clara e precisa como o estudo será executado. Deste modo, este trabalho realizou diferentes revisões bibliográficas sobre o tema da importância da contabilidade para o MEI em livros, em revistas acadêmicas científicas disponíveis on-line e impressas, reunindo e comparando os diferentes dados encontrados nas fontes de consulta e listando os principais fatores relação ao tema do estudo. 


\subsection{PROCEDIMENTOS METODOLÓGICOS}

Os procedimentos metodológicos ajudarão a nortear o que será desenvolvido ao longo do trabalho. Para Menezes et al. (2019) os procedimentos metodológicos são procedimentos detalhados do que serão abordados ao realizar o estudo a fim de atingir os objetivos que são propostos. A partir da afirmação dos autores percebe-se o quão importante e necessário detalhar a forma que será construído o estudo, bem como todos os procedimentos que serão utilizados.

Nessa etapa do desenvolvimento do estudo é importante detalhar todos os procedimentos que serão desenvolvidos ao longo da pesquisa, assim o método utilizado para a desenvolvimento deste estudo foi baseado em pesquisa de revisão bibliográfica que para Gil (2017) a pesquisa bibliográfica é aquela que está disponível de forma pública para ser acessada que tem como pesquisa básica através de buscas em informações e dados, tendo como objetivo principal demonstrar para o MEl a importância que a contabilidade traz para seu negócio.

\subsubsection{QUANTO À NATUREZA}

Não basta pesquisar, é preciso saber bem o que e como se pesquisa. Para Severino (2016), quanto a natureza neste estudo será utilizada a pesquisa básica, pois reúne estudo que tem o propósito de preencher lacunas acerca do conhecimento porque a pesquisa tem propósitos distintos que busca descrever a realidade da importância da contabilidade para o MEI. A partir da revisão bibliográfica que será reunido conceitos e teorias que ajudarão a nortear a condução do estudo.

\subsubsection{QUANTO AOS FINS}

Toda pesquisa realizada possui um propósito em relação ao que foi estabelecido no decorrer do desenvolvimento da proposta de estudo, dessa maneira, trata-se de pesquisa descritiva que tem como objetivo descrever todos os problemas encontrados ao decorrer da pesquisa. De acordo com Vergana (2016) a pesquisa

RC: 98793

Disponível em:

https://www.nucleodoconhecimento.com.br/contabilidade/contribuicao-do-contador 
descritiva mostra características de uma determinada população e um determinado fenômeno porque visa descrever percepções, expectativas e sugestões ao MEI da importância que a contabilidade tem para sua gestão na empresa a partir disso mostrar de forma descritiva todas as vantagens de se ter a contabilidade dentro da organização. Além disso, será utilizada pesquisa exploratória sobre o tema da pesquisa que de acordo com Fonseca (2012) permite explorar mais determinado assunto.

\subsubsection{QUANTO AOS MEIOS}

Os estudos quanto aos meios têm como principal foco analisar os problemas que são encontrados no decorrer do estudo que serão solucionados ou não porque os meios para alcançar os resultados da investigação são diversos, conforme Lakatos e Marconi (2016), a partir do desenvolvimento do estudo é um estudo qualitativo que tem como foco estudar a fundo sobre as vantagens de se utilizar a contabilidade.

\section{CONSIDERAÇÕES FINAIS}

O objetivo principal deste estudo foi mostrar a importância que a contabilidade traz para o MEl e para o seu negócio, pois ter um contador andando lado a lado nos negócios é essencial para uma empresa porque pode ajudar no desempenho e na situação econômica da mesma, além de nortear o empresário a saber qual decisão tomar para não prejudicar o desempenho da organização além dos benefícios para os negócios, principalmente para a tomada de decisões que irão afetar de maneira positiva ou não os negócios.

Diante disso, o MEI não tem por obrigação ter um contador na sua empresa, mas o estudo desenvolvido ao longo deste trabalho sugere que é importante para ele porque contribuirá com os negócios, pois é um novo empreendedor e partir da ajuda de um contador saberá entender a situação da sua empresa e qual decisão tomar, quando houver necessidade além de saber um pouco mais sobre como funciona o sistema tributário, o andamento dos negócios e a situação real da empresa. Embora 
não seja uma exigência para o $\mathrm{MEI}$ que ele possua um contador auxiliando-o nos negócios, pois ele pode fazer isso de maneira própria, o que é mais vantajoso para ele.

A pergunta norteadora deste estudo é: de que forma é possível demonstrar a relevância da contabilidade para o MEI? Foi respondida da seguinte maneira: demonstrando que o contador ajuda a resolver não somente questões de números, mas para saber o andamento e o rumo que os negócios estão tomando para empresa, pois a contabilidade abre um leque de oportunidades para esse novo microempreendedor a trabalhar de maneira correta e eficiente para não se prejudicar nas decisões que irá tomar no decorrer do desenvolvimento dos negócios, visto que é novo na área de saber como lidar com os negócios da empresa, por fim o contador dentro da empresa pode ajudar a nortear todos os processos que serão realizados.

Portanto, conclui-se que é de suma importância a contribuição do contador para as empresas, principalmente para $0 \mathrm{MEI}$, na qual o contador tem um papel indispensável na sua empresa, onde ele orienta, auxilia e faz com que a empresa se organize e tenha grande sucesso.

\section{REFERÊNCIAS}

AGOSTINI, C.; CARVALHO, J. T. de. A Evolução da Contabilidade: seus avanços no Brasil e a Harmonização com as Normas Internacionais. Instituto de Ensino Superior Tancredo de Almeida Neves. Armário de Produção. Ano, v. 1, 2012.

BASTOS FILHO, L. A. B. A importância do contador para o microempreendedor individual. 2019.

BEHLING, G.; LENZI, F. C. A Relação entre Competências Empreendedoras e Comportamento Estratégico: um estudo com Microempreendedores Individuais (MEI). Encontro de Estudos sobre Empreendedorismo e Gestão de Pequenas Empresas, v. 11, 2016. 
BEUREN, I. M.; et al. Barreiras e possibilidades de aplicação da contabilidade gerencial em micro e pequenas empresas por meio de empresas de serviços contábeis. Contexto, v. 13, n. 24, p. 79-92, 2013.

BRINCKMANN, R. Contabilidade básica. Florianópolis: Departamento de Ciências da Administração/UFSC, 3. ed. p. 110, 2014.

CHAVES, F. C.; MUNIZ, É. G. Contabilidade tributária na prática. $4^{a}$ ed. São Paulo: Atlas, 2012.

CERQUEIRA, M. da S. do N. Mídias sociais e microempreendedores individuais: uma interação cada vez mais globalizada para o empreendedor. 2020.

CREPALDI, S. A. Contabilidade gerencial, teoria e prática. $4^{a}$ ed. São Paulo: Atlas, 2013.

CHIAVENATO, I. Empreendedorismo: dando asas ao espírito empreendedor. São Paulo: Saraiva, 2012.

COELHO, P. M. N. Rumo à indústria 4.0. Dissertação (Mestrado em Engenharia e Gestão Industrial) - Faculdade de Ciências e Tecnologias, Departamento de Engenharia Mecânica. Universidade de Coimbra. Coimbra, Portugal, 2016. Acesso em: 22 de setembro de 2021.

COSTA, M. L.; FEITOSA FILHO, R. I. A importância da contabilidade no processo de desenvolvimento do microempreendedor individual (MEI). Revista Brasileira de Administração Científica, v. 10, n. 2, p. 154-163, 2019.

CHUPEL, J. F.; et al. A importância da contabilidade para microempreendedor individual. Revista Eletrônica da Faculdade de Alta Floresta, v. 3, n. 2, 2014.

FONSECA, J. J. S. da. Metodologia da pesquisa científica. Ceará: Universidade Estadual do Ceará, 2012. 
GARCIA, R. M.; BEZERRA, D. O. A importância da contabilidade gerencial para pequenas e médias empresas em meio a pandemia do COVID-19. Revista Campo do Saber, v. 6, n. 2, 2021.

GRECO, A. L.; AREND, L. Contabilidade: teoria e prática básicas. ed. 05, São Paulo Saraiva, 2016.

GIL, A. C. Como elaborar projetos de pesquisa. ed. 06, São Paulo: Atlas, 2017.

GONDIM, M. D.; et al. Crise versus empreendedorismo: Microempreendedor Individual (MEI) como alternativa para o desemprego na região petrolífera da Bacia de Campos e regiões circunvizinhas. Pensar Contábil, v. 19, n. 70, 2018.

LAKATOS, E. M.; MARCONI, M. de A. Fundamentos de Metodologia Científica. 8. ed. 3ª Reimpressão. São Paulo: Atlas, 2016.

LUNELLI, R. L. A contabilidade e o avanço da tecnologia. Disponível em: $<$ http://www.portaldecontabilidade.com.br/tematicas/contabilidadeetecnologia.htm>. Recuperado em: 01 maio, 2021.

LOPES, K.; BURIOLA, M. C. M. A evolução da contabilidade. In: Anais Colóquio Estadual de Pesquisa Multidisciplinar (ISSN-2527-2500) \& Congresso Nacional de Pesquisa Multidisciplinar. 2019.

MAZZA, A. Manual de Direito Tributário. ed. 04, Saraiva. São Paulo. 2018.

MACHADO, P. B. Manual do Processo Eletrônico de Inscrição do Microempreendedor Individual (MEI). São Paulo: Editora Perse, 2012.

MENEZES, A. H. N.; et al. Metodologia cientifica teórica e aplicação na educação a distância. Petrolina: PE, 2019. 
OLIVO, A. M.; BOSCHILIA, L. Contabilidade geral e gerencial: conceitos introdutórios para os cursos superiores de tecnologia. Florianópolis: Publicações do IF-SC, p. 102, 2012.

PAIVA, E. de P. de; et al. A utilidade da contabilidade: Um estudo realizado sobre o ponto de vista dos Microempreendedores Individuais. 2020.

BLB BRASIL, Contabilidade e sua importância: você sabe como funciona? 2018. Disponível em: <https://www.blbbrasil.com.br/>. Acesso em: 22 set. 2021.

SEBRAE, SERVIÇO BRASILEIRO DE APOIO ÀS MICRO E PEQUENAS EMPRESAS. Fatores condicionantes da mortalidade de empresas - pesquisapiloto realizada em Minas Gerais. Brasília: Sebrae, 2020.

AMORIM, V. S.; CARDOSO, P. H. G. Importância do microempreendedor individual (mei) na geração de renda e empregos no bairro moreiras na cidade de Acopiara, Ceará, Brasil. Revista Livre de Sustentabilidade e Empreendedorismo, v. 6, n. 2, p. 201-220, 2021.

STAATS, C.; DE MACEDO, F. As Inovações Tecnológicas e a Contabilidade Digital: Um Estudo de Caso sobre a Aceitação da Contabilidade Digital no Processo de Geração de Informação Contábil em um Escritório Contábil de Joinville/SC. Revista Controladoria e Gestão, v. 2, n. 1, p. 348-369, 2021.

SEVERINO, A. J. Metodologia do trabalho científico. ed. 24, São Paulo: Cortez, 2016.

SOUZA, A. L.; et al. A importância da contabilidade para o microempreendedor individual. Brazilian Journal of Health Review, v. 4, n. 3, p. 13341-13354, 2021.

TESSMANN, G. de M. O desafio da contabilidade digital para os profissionais contábeis. 2011. 
VERGANA, S. Projetos e Relatórios de Pesquisa em Administração. ed. 16, São Paulo: Atlas, 2016.

VOLNEI, C. et al. A evolução da contabilidade e seus objetivos. Universidade Luterana do Brasil-ULBRA, p. 1-16, 2010.

Enviado: Setembro, 2021.

Aprovado: Outubro, 2021.

RC: 98793

Disponível em:

https://www.nucleodoconhecimento.com.br/contabilidade/contribuicao-do-contador 